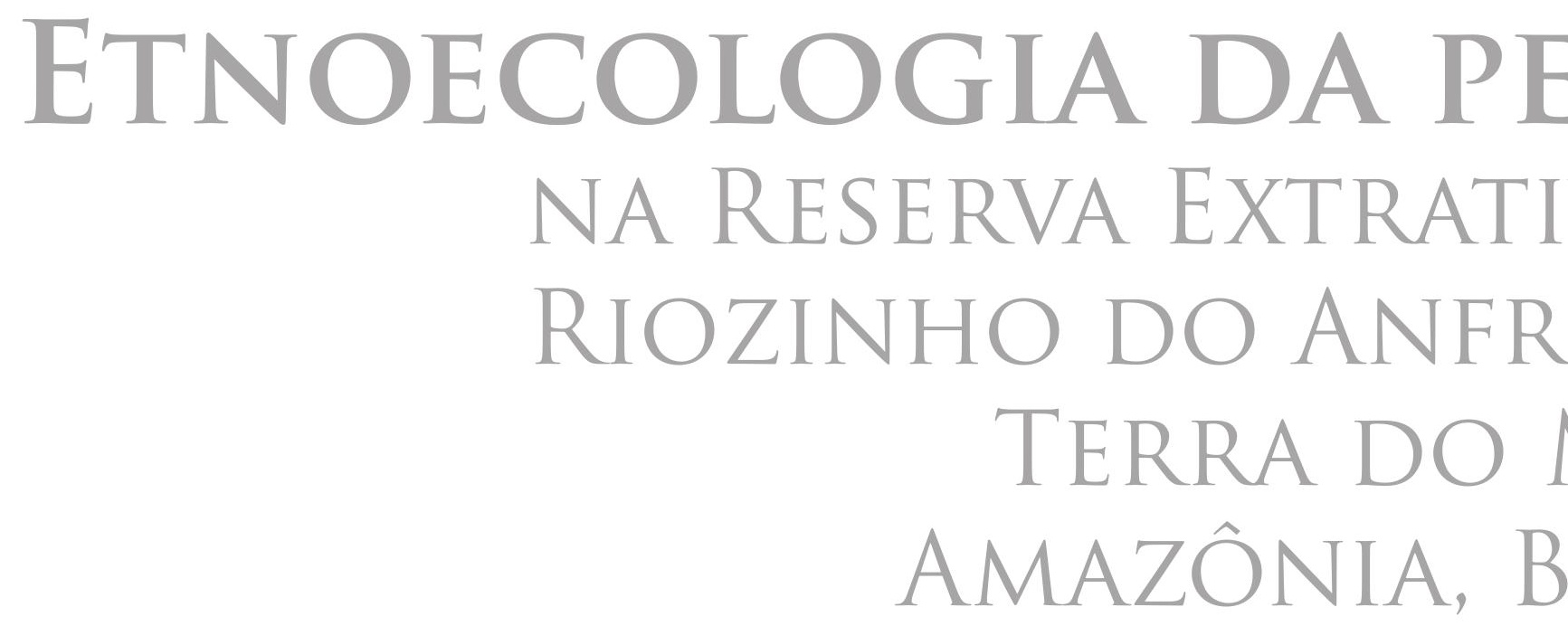




\section{ETNOECOLOGIA DA PESCA}

NA RESERVA EXTRATRIVISTA RIOZINHO DO ANFRÍSIO TERRA DO MEIO, AMAZÔNIA,BRASIL

\section{F LÁ VIO B E Z E R RA B A R ROS}




\title{
ETNOECOLOGIA DA PESCA NA RESERVA EXTRATIVISTA RIOZINHO DO ANFRÍSIO - TERRA DO MEIO, AMAZÔNIA, BRASIL
}

\section{Resumo}

Este artigo apresenta alguns aspectos etnoecológicos da atividade pesqueira na Reserva Extrativista Riozinho do Anfrísio, área protegida (AP) localizada no município de Altamira, Pará. Esta AP foi criada em 2004 através de uma iniciativa conjunta dos ribeirinhos e movimentos sociais da região da Transamazônica e Xingu. Dentre as diversas atividades produtivas desenvolvidas pelos ribeirinhos, a pesca é uma das mais importantes. Através de métodos atinentes ao campo da etnoecologia, foram estudadas as cosmologias e os saberes locais acerca da ictiofauna de importância alimentar e comercial. O estudo apontou que os ribeirinhos demonstram grande conhecimento sobre os ecossistemas e a biodiversidade de peixes, o qual deve ser reconhecido como parte do patrimônio biocultural local. Em termos de estratégias para a conservação dos recursos naturais estes saberes devem ser igualmente valorizados.

Palavras-chave: Pesca, etnoecologia, Terra do Meio, Amazônia Brasileira.

\section{FISHING ETHNOECOLOGY IN RIOZINHO DO ANFRÍSIO EXTRACTIVE RESERVE - TERRA DO MEIO, BRAZILIAN AMAZON}

\begin{abstract}
This article presents some ethnoecological aspects of the fishing activity in Riozinho do Anfrísio Extractive Reserve, a protected area (PA) located in the municipality of Altamira, State of Pará, Brazil. This PA was created in 2004 through a joint initiative of the riverines and Transamazonian Highway and Xingu social movements. Fishing is one of the most important productive activities in this extractive reserve. By using ethnoecological methods this study addresses the cosmologies and the knowledge related to the use of fish for subsistence and commercial purposes. Our results showed that the riverine people demonstrate a high level of knowledge regarding their ecosystems and the fish biodiversity, which must be considered part of the local biocultural heritage. This knowledge must be also integrated in the conservation strategies taken place in that region.
\end{abstract}

Keywords: Fishing, ethnoecology, Terra do Meio, Brazilian Amazon. 


\section{ETHNOÉCOLOGIE DE LA PÊCHE DANS LA RÉSERVE EXTRACTIVISTE RIOZINHO DO ANFRÍSIO - TERRA DO MEIO, AMAZONIE, BRÉSIL}

\section{Résumé}

Cet article révèle quelques aspects ethnoécologiques de l'activité de pêche dans la Réserve Extractiviste Riozinho do Anfrísio, aire protégée (AP) située dans la municipalité de Altamira, Pará. Cette AP a été créée en 2004 par le biais d'une initiative conjointe des sociétés traditionnelles amazoniennes (les “ribeirinhos') et des mouvements sociaux de la région Tranzamazonienne et du Xingu. Parmi les différentes activités productives employéss par les "ribeirinhos", la pêche est l'une des plus importantes. Par des méthodes du champ de l'eth'oécologie, il a été étudié les cosmologies et les savoirs locaux sur la faune ichtyologique d'importance alimentaire et commerciale. L'étude a révélé que les "ribeirinhos" ont des savoirs importante sur les écosystèmes et la biodiversité des poissons, qui doivent être reconnus comme faisant partie du patrimoine bioculturel local. Em termes de stratégies pour la conservation des ressources naturelles, tels savoirs doivent être également valorisés.

Mots-clés: pêche, ethnoécologie, Terra do Meio, Amazonie brésilienne. 
“(...) Só eu conheço meus pesqueiros. Eu vou, estudo o local, observo, depois marco esse local e no final de junho volto para fazer a limpeza. Todo verão eu volto lá. Passo seis meses sem ir lá para dar tempo de aparecer muito peixe. Eu, por exemplo, tenho 45 pesqueiros só de tucunaré (...)" (Sr. C., Pescador da ResEx Riozinho do Anfrísio).

\section{COMO TUDO COMEÇOU...}

Gostaria de iniciar este texto falando da minha primeira experiência com o povo da Reserva Extrativista (ResEx) Riozinho do Anfrísio. $\mathrm{Na}$ época em que começou o burburinho acerca da possível criação da Reserva Extrativista Riozinho do Anfrísio, entre o final dos anos 1990 e início dos anos 2000, quando a invasão (ou melhor, a grilagem) pela C. R. Almeida e outros atores indesejados estava se intensificando na Terra do Meio, o Ministério do Meio Ambiente, na altura sob a responsabilidade da Ministra Marina Silva, encomendou diversos estudos sobre o território. Um desses estudos, dirigido ao Riozinho do Anfrísio, foi feito por um conjunto de organizações parceiras, dentre elas o então Laboratório Agroecológico da Transamazônica (LAET/NCADR-UFPA). Os estudos tinham como finalidade entender inicialmente algumas características socioeconômicas da localidade e as principais necessidades da população nos campos da segurança, saúde, educação, documentação, condições de moradia, dentre outras. Infelizmente, por razões diversas, não pude participar da expedição (naquela altura eu fazia parte da equipe do LAET). À época, entre
2004 e 2005, eu estava amadurecendo as ideias para o projeto de tese de doutoramento, e a professora Soraya Carvalho - do Núcleo de Ciências Agrárias e Desenvolvimento Rural da UFPA -, que participou do estudo, voltou encantada da região, porém consciente do grande desafio que era trabalhar naquele terreno. Soraya contou que os ribeirinhos ${ }^{1}$ relatavam os horrores que enfrentaram sob o domínio dos grileiros e toda sua tropa de malfeitores. Muitos moradores relataram, e ainda relatam, as constantes proibições que foram impostas pelos homens da grilagem, impedindo os moradores do Riozinho de acessarem seus castanhais e lagos fartos de peixes, sob a alegação de que a terra tinha dono. Mas, em outra medida, demonstravam a intrínseca ligação que tinham com as matas e rios da região e como esta complexa relação natureza e sociedade se constituía. Quando Soraya regressou do Riozinho do Anfrísio, disse-me: eu acho que deverias fazer tua tese de doutoramento lá! Lembro que muitos amigos de Altamira me incentivaram a desenvolver meu campo no Riozinho, o qual iria produzir a primeira tese de doutorado da região. E eu, obviamente, fiquei bastante motivado para conhecer o território, mas este momento não aconteceu, até que eu fizesse o projeto de tese e, somente em maio de 2008, quando voltei ao Brasil para dar início ao trabalho de campo, pois já tinha iniciado o doutoramento na Universidade de Lisboa, tive a oportunidade de realizar a primeira expedição ao Riozinho do Anfrísio. Esta viagem, ocorrida no inverno daquele ano, foi efetivada 
junto às duas professoras que tinham sido designadas para lecionar, Creuza e Érika, que assim como eu, estavam indo para o Riozinho do Anfrísio pela primeira vez. Assim, nossa viagem num barco de médio porte, que durou cerca de seis dias, aconteceu em meio às conversas sobre educação, método Paulo Freire de alfabetização, e como seria viver e trabalhar no Riozinho, um lugar "distante" e sem luz, no meio da Floresta Amazônica, na Bacia do Xingu. Nosso imaginário viajava conosco, pois além de fotografias e relatos, meu contato com a realidade do lugar se deu por meio de algumas reuniões com os ribeirinhos que passavam alguma temporada na cidade de Altamira, além do contato com o instigante romance de André Costa Nunes, intitulado "A batalha do Riozinho do Anfrísio". Importa destacar que meu trabalho de campo durante esta expedição se restringiu a apenas duas comunidades: Morro Verde e Praia do Anfrísio (na época todo mundo chamava Praia do Frizan). Tal decisão de conhecer as duas comunidades se deveu ao fato de depender de uma carona para regressar a Altamira, uma vez que tais colocações ${ }^{2}$ ficam mais próximas ao Rio Iriri, onde eu deveria encontrar o barco do IBAMA para retornar à Princesinha do Xingu, como Altamira é carinhosamente apelidada. Várias foram as perguntas que me instigaram a realizar o doutoramento no Riozinho, dentre elas: como se dá a relação sociedade e natureza numa das regiões mais conservadas da Amazônia Oriental? Qual o protagonismo dos povos ribeirinhos no que diz res- peito à conservação da floresta? Como as comunidades locais se apropriam da natureza? Como a biodiversidade influencia a organização social e a cultura material e imaterial? E como os sapos - considerados animais biondicadores - podem contribuir para o entendimento da dinâmica do uso dos ecossistemas locais pelos ribeirinhos? Neste ensaio irei apresentar um estudo sobre a pesca local, enfatizando os aspectos etnoecológicos desta importante atividade que demarca um modo de vida, uma identidade, enfim, um universo repleto de saberes e tramas.

\section{CONEXÃO PESCA E ETNOECOLOGIA NA AMAZÔNIA}

As comunidades tradicionais, diferentemente das sociedades urbanas industriais, de modo geral retiram diretamente da natureza os recursos necessários para a sua subsistência e reprodução sociocultural. Estas sociedades, incluindo os povos indígenas, são detentoras de um rico e complexo conjunto de conhecimentos e estratégias de uso dos recursos naturais presentes em seus territórios. Vários autores ao redor do mundo têm estudado como estas comunidades se relacionam e utilizam os recursos da natureza (Toledo et al. 2003, Ramires et al. 2007, Xu et al. 2006, Begossi 2006, Silvano \& Begossi 2005, Begossi \& Silvano 2008). Muitos desses estudos, além de apresentar o conhecimento ecológico tradicional das comunidades, o qual constitui um precioso patrimônio cultural a ser valorizado, vem enfatizando a importância da participação dos po- 
vos locais em discussões que envolvem a conservação da biodiversidade e dos recursos naturais, em particular em unidades de conservação. Diversos estudos, como aqueles desenvolvidos por Costa-Neto \& Marques (2000), Rozzi et al. (2006), Alves et al. (2007), destacaram que a integração entre cientistas e populações locais pode ser extremamente relevante para a conservação da biodiversidade em escalas local e mundial, em particular quando existem conflitos entre os interesses do Estado e as expectativas das comunidades locais.

$\mathrm{Na}$ Amazônia, as principais atividades produtivas das comunidades tradicionais são a agricultura de base familiar, a caça, a coleta de produtos da floresta (comumente denominada de extrativismo) e a pesca. Esta última, objeto central deste ensaio, pode ser caracterizada como atividade comercial e/ou de subsistência (Almeida et al. 2003). Nesta região, a pesca de interesse comercial tem se expandido desde a década de 1970 e 1980, influenciada pela demanda das populações urbanas por pescado e pelo crescimento das indústrias de processamento de peixes para exportação (Almeida et al. 2003). A pesca artesanal (costeira e fluvial), por sua vez, provê alimento e trabalho para muitas comunidades, especialmente em países tropicais em desenvolvimento, onde a maior parte da captura do pescado é feita por pescadores artesanais (Derman \& Ferguson 1995). Em geral esta atividade é caracterizada por um complexo conhecimento etnoecológico que é transmitido oralmente para as gerações futuras, além de envolver um grande número de espécies e cosmologias que giram em torno de seres sobrenaturais que habitam o universo das águas. De acordo com Silvano (2004), estudos abordando simultaneamente o conhecimento popular das populações e o conhecimento científico podem ser potencialmente relevantes tanto para os pescadores como para os cientistas. Para estes últimos, a Etnoecologia pode providenciar novas informações e linhas de direção para as pesquisas, a fim de se pensar também o desenvolvimento de diretrizes que sejam compatíveis com a realidade dos pescadores. A Etnoecologia é uma ciência interdisciplinar, que navega na fronteira entre as Ciências Sociais e as Ciências Naturais, tendo como objetivo central entender como as sociedades humanas utilizam e percebem o ambiente natural que está em sua volta; entretanto, diferentes autores têm apresentado definições aproximadas para este campo do conhecimento (Nazarea 1999, Marques 2001, Toledo 2001). De acordo com Marques (1991:49), a Etnoecologia pode ser assim definida:

"É o estudo das interações entre a humanidade e o resto da ecosfera, através da busca da compreensão dos sentimentos, comportamentos, conhecimentos e crenças a respeito da natureza, característicos de uma espécie biológica (Homo sapiens) altamente polimórfica, fenotipicamente plástica e ontogeneticamente dinâmica, cujas novas propriedades emergentes geram múltiplas descontinuidades com o resto da própria natureza. Sua ênfase, pois, deve ser na diversidade biocultural e o seu objetivo principal, a integra- 
ção entre o conhecimento ecológico tradicional e o conhecimento ecológico científico."

O modo como o conhecimento, os usos e os significados dos peixes se organizam nos diferentes grupos humanos é tema de investigação da Etnoictiologia e esta pode ser interpretada como a busca da compreensão do fenômeno da interação entre o ser humano e os peixes, englobando aspectos tanto cognitivos quanto comportamentais (Marques 1995). Em termos amazônicos, diferentes estudos, como os desenvolvidos, por exemplo, por Smith (1979), Furtado (1993), Murrieta (2001), deram conta de registrar os diferentes aspectos da atividade pesqueira na Amazônia, dentre os quais os conhecimentos técnicos e simbólicos. Neste contexto, cada vez mais a Etnoecologia deveria ser valorizada como elemento relevante a ser considerado em programas de conservação da natureza, particularmente em áreas protegidas (AP's), uma vez que estas envolvem mais de perto a participação de cientistas e Instituições preocupados com a preservação dos ecossistemas e seus respectivos recursos naturais. Neste texto apresento alguns aspectos da etnoecologia da pesca no Riozinho do Anfrísio e aponto algumas ideias acerca da importância da valorização dos saberes locais para uma gestão compartilhada dos recursos naturais.

\section{ÁREA DE ESTUDO E COMUNIDADE HUMANA}

A ResEx Riozinho do Anfrísio
(54³9'18.28"W, 445'33.98"S) (Figura 1) apresenta uma extensão territorial de 736.340 ha e está localizada no município de Altamira, estado do Pará, Norte do Brasil. O município de Altamira situa-se no Sudoeste do Pará, na Região Político-Administrativa denominada de Transamazônica e Xingu. Altamira possui uma extensão de 159.695,94 km² e uma população de 98.750 habitantes, a maioria vivendo na zona urbana (IBGE 2010). A ResEx foi implementada em 2004 pelo decreto presidencial $\mathrm{N}^{\circ} 215$, de 9 de Novembro. A área está inserida na Bacia Hidrográfica do Rio Xingu, a qual nasce no Planalto dos Guimarães, no estado do Mato Grosso e deságua no Rio Amazonas, no estado do Pará, formando uma das maiores bacias hidrográficas do Brasil, com 511.891,00 milhões de ha de superfície, dos quais 65\% estão no Pará (Velásquez et al. 2006).

A ResEx Riozinho do Anfrísio está distante cerca de $400 \mathrm{~km}$ da sede do município de Altamira. O território que abriga esta unidade de conservação (UC) é conhecido como Terra do Meio (TdM), o qual compreende áreas do interflúvio dos rios Xingu e Tapajós, de onde veio seu nome. A TdM constitui um mosaico de conservação da natureza formado por oito AP's federais, sendo cinco de uso sustentável (com populações humanas) e três de proteção integral (sem populações humanas), além de Terras Indígenas (TI's), que são espaços protegidos com outro estatuto legal. Integra ainda esse mosaico de áreas protegidas (AP's), a Floresta Estadual do Iriri e a Área de 
Proteção Ambiental (APA) Triunfo do Xingu, UC's de estatuto estadual, sendo geridas pelo governo do Estado do Pará.

Os ribeirinhos do Riozinho do Anfrísio são fruto da miscigenação entre comunidades indígenas locais e migrantes nordestinos e de outras localidades da Amazônia que vieram para a região na época da borracha, entre o fim do século XIX e início do século XX.

A ideia de criação da UC surgiu de uma boa parte da população local em diálogo com os movimentos sociais da região da Transamazônica e Xingu, frente às constantes ameaças sofridas pela invasão de suas terras por madeireiros e grileiros, que colocavam em causa a permanência dos ribeirinhos em seus territórios sagrados, bem como o acesso aos recursos naturais.

Aproximadamente 57 famílias (com cerca de 300 pessoas) vivem hoje no Riozinho do Anfrísio, onde desenvolvem atividades como a pesca (comercial e de subsistência), a caça, a coleta de produtos da floresta (seringa, óleos de copaíba e andiroba, mel, cipós, frutos, madeira, dentre outros), além de desenvolverem agricultura itinerante e criação de pequenos animais (galinha e pato).

\section{MÉTODOS}

Os principais métodos utilizados foram a etnografia, a entrevista informal e semiestruturada e a observação participante. Segundo Amorozo \& Viertler (2008), a pesquisa de campo na área de Etnobiologia e Etnoecologia visa propiciar o desenvolvimento da sensibilidade do pesquisador, familiarizá-lo com peculiaridades culturais da comunidade dos seus informantes, muitas das quais ele passa a "compreender", sentir e intuir a partir de conversas informais. A percepção pessoal de tais pecu-

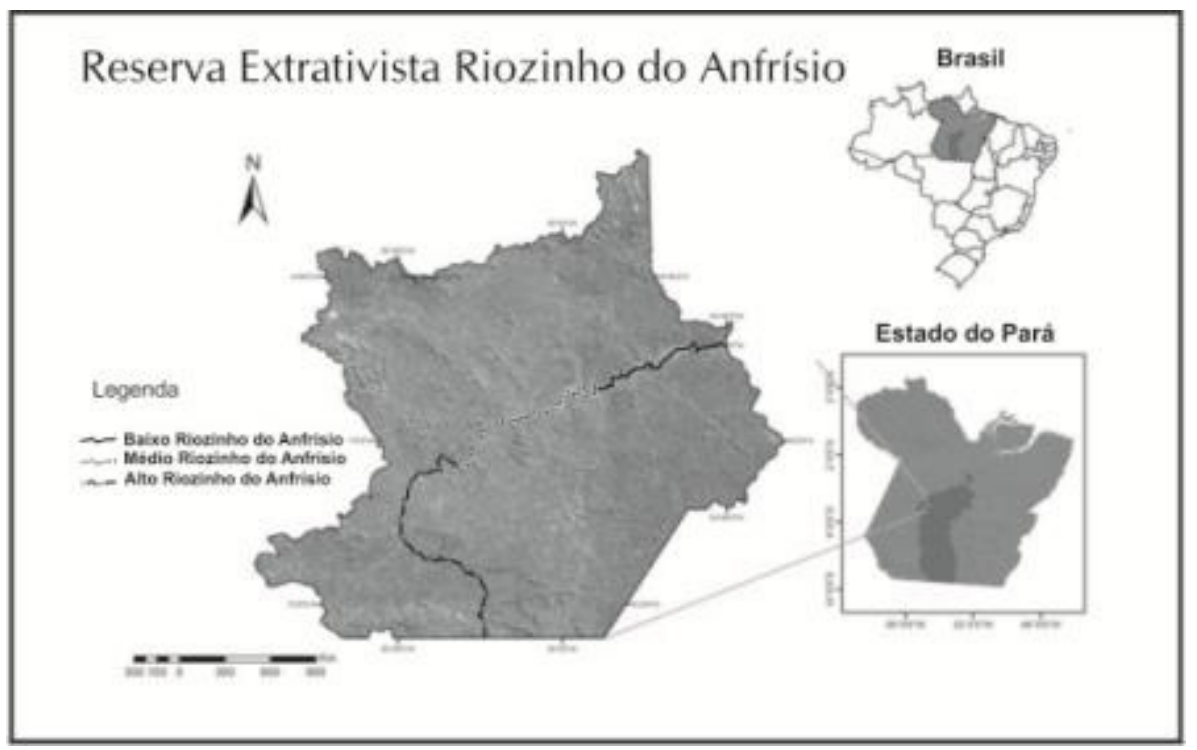

Figura 1 - Mapa de localização da Reserva Extrativista Riozinho do Anfrísio, Altamira, Pará. 
liaridades e o aprendizado cuidadoso de como se conduzir na comunidade sem causar maiores transtornos constituem elementos importantes para o bom andamento do trabalho de pesquisa. Desse modo, estudos serão bem sucedidos se a inserção do pesquisador num determinado grupo humano ocorrer de modo satisfatório.

A entrevista informal é aquela em que há falta total de controle ou estrutura, e a que mais se aproxima de uma conversa normal. É a mais utilizada durante as primeiras fases da observação participante, quando se está conhecendo a situação, e também para aumentar ou estreitar relações com os interlocutores e detectar novos tópicos de interesse. Já a entrevista semiestruturada visa mergulhar de forma mais aprofundada num determinado tema que se investiga.

A observação participante, de acordo com Martins (1996) e Spradley (1980), é uma metodologia elaborada principalmente no contexto da pesquisa antropológica. Trata-se de estabelecer uma adequada participação dos pesquisadores dentro dos grupos observados de modo a reduzir a estranheza recíproca. Os pesquisadores são levados a compartilhar os papéis e os hábitos dos grupos observados para estarem em condição de observar fatos, situações e comportamentos que não ocorreriam ou que seriam alterados na presença de estranhos. Foi Malinowski (1978) quem sistematizou as regras metodológicas para a pesquisa antropológica, pois a ideia que caracterizava o método era a de que apenas através da imersão no cotidiano de outra cultura, o antropólogo

poderia chegar a compreendê-la. De fato, o envolvimento com a comunidade local foi de extrema relevância para a compreensão do universo etnoecológico da pesca. Para Geertz (2008:15), entretanto, praticar etnografia não é somente estabelecer relações, selecionar informantes, transcrever textos, levantar genealogias, mapear campos, manter um diário, mas "sim o esforço intelectual que ele (o método etnográfico) representa: um risco elaborado para uma descrição densa".

As principais questões consideradas no roteiro de entrevista contemplaram aspectos acerca dos nomes de peixes utilizados, época do ano em que as espécies ocorrem com maior frequência, instrumentos de pesca mais usados por espécie, informações da ecologia trófica, ambientes de ocorrência, etologia e aspectos peculiares das espécies (termo localmente conhecido como "ciência”). A identificação das espécies de peixes se deu de duas maneiras. A primeira ocorreu entre os próprios pescadores, os quais indicavam os nomes locais de cada espécie. À medida que as entrevistas iam sendo realizadas, tais etnoespécies eram confirmadas de acordo com o maior percentual de reconhecimento pelos pescadores. A segunda foi através da identificação taxonômica. Para tal, utilizei fotografias das espécies, as quais foram analisadas pelos especialistas Mauricio CamargoZorro, do Instituto Federal do Pará, e Janice Muriel F. L. da Cunha, da Universidade Federal do Pará. 
PESCA NO RIOZINHO DO ANFRÍSIO: ALGUMAS CARACTERÍSTICAS

A pesca é uma das atividades mais importantes na vida dos ribeirinhos do Riozinho do Anfrísio, pois sua relevância não se dá apenas no campo da subsistência, mas é elemento essencial da cultura local. O peixe representa uma fonte importante de proteína na dieta dos moradores, sendo o alimento mais consumido nesta população junto com a farinha de mandioca. Alguns estudos desenvolvidos na Amazônia também destacaram a importância do peixe como principal fonte de proteína animal na dieta de ribeirinhos (Batista et al. 1998, Murrieta et al. 2004, Silva 2007).

A pesca artesanal na UC se constitui como uma das principais atividades produtivas das famílias locais. $\mathrm{Na}$ maior parte do ano essa prática tem a função exclusiva de subsistência. No período compreendido entre julho e novembro (verão) assume também o caráter de obtenção de renda. Entre novembro e janeiro, período em que a pesca se torna "proibida" por lei, no caso das espécies que se reproduzem nesta época do ano e que têm valor comercial, tal atividade é praticada apenas com função de subsistência. Seja para fins comerciais ou consumo das famílias residentes, tanto as entrevistas como as observações indicaram que a atividade pesqueira é permeada por um conjunto de regras e condutas que dinamizam o cotidiano dos sujeitos.

Quanto ao espaço utilizado, existem locais que são classificados como sendo de uso restrito, correspondendo ao trecho do rio que compreende a colo- cação do pescador, com limites claramente conhecidos pelos moradores; e coletivos, onde qualquer residente $\mathrm{da}$ ResEx pode pescar. Os igarapés do Pereira e do Limão (ver Figura 2) são as áreas de pesca comunais dentro da UC; além destas áreas, as colocações abandonadas podem ser utilizadas para pesca por quaisquer moradores. Portanto, pescar em área que não pertença à colocação do pescador constitui falha grave. Tal conduta é vista com reprovação entre os moradores de toda a área, mas, segundo os entrevistados, dificilmente ocorre esse tipo de comportamento. Somente em caso de convite ou com permissão prévia é que um morador pode pescar em outra área que não seja a sua.

$\mathrm{Na}$ época das cheias (dezembro a maio) geralmente a pesca é caracterizada como uma atividade solitária, comumente realizada pelos homens e sem horários fixos, pois o objetivo principal é a obtenção de um quantitativo de peixe suficiente para alimentar a família naquele dia. $\mathrm{Na}$ pesca comercial, toda a família, incluindo as mulheres ou parentes mais próximos, participa dessa atividade, onde cada membro realiza uma função distinta.

Com relação aos apetrechos de pesca utilizados, destacam-se: a) a zagaia, b) a malhadeira, c) o caniço, d) a tarrafa, e) a tela (ou linha); f) o espinhel; g) a tiradeira e h) arco e flecha (Quadro 1), os quais apresentam diversas semelhanças com as descrições feitas por Smith (1979) e Silvano (2004). Ainda é utilizada a técnica da lanternagem, que consiste na procura ativa dos peixes no período noturno com o auxílio de 


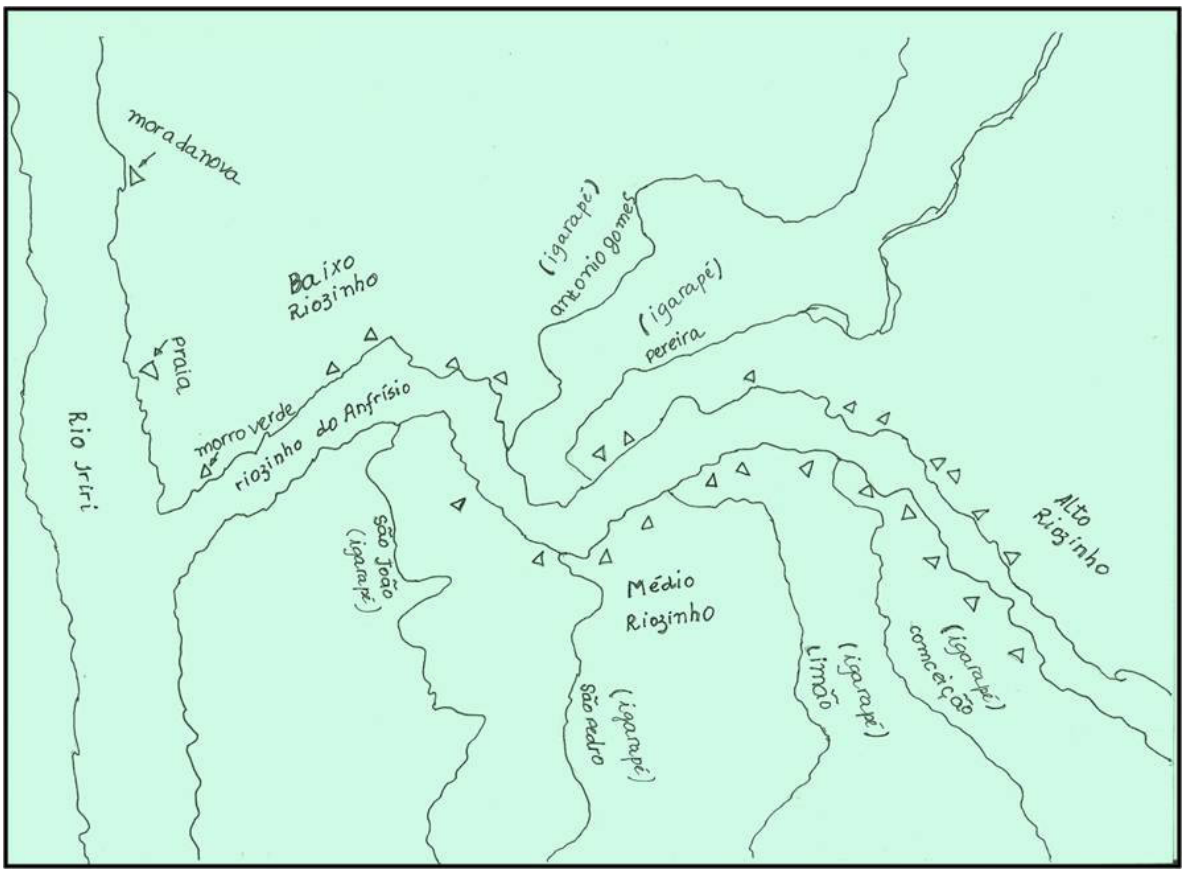

Figura 2 - Mapa mental do Riozinho do Anfrísio, elaborado por Herculano Filho (Lôro), morador local. Legenda: triângulos representam as colocações; linhas adjacentes representam os principais igarapés; setas indicam áreas comunais de pesca.

uma lanterna e um facão. A tapagem é utilizada para peixes que realizam o comportamento de piracema, porém é raramente empregada. Segundo os interlocutores, para cada espécie de peixe utiliza-se um ou mais tipos de apetrechos, que pode se mostrar mais eficiente de acordo com a espécie, o local de ocorrência e a época do ano (Quadro 2). De acordo com as minhas observações, a linha e o arco e flecha são os instrumentos mais utilizados, principalmente no inverno, ao passo que no verão, a malhadeira e a tarrafa são bastante utilizados, os quais são trazidos de fora da Reserva pelos "patrões da pesca"3 e vendidos aos pescadores. O transporte utilizado para a pesca é a canoa a remo ou motor.

\section{ETNOECOLOGIA}

"Eu não mato ariranhas porque elas estão aqui na mesma luta que nós. Estão em busca do que comer. No caso, os peixes". (Sr. H., morador da ResEx).

Registrei 34 espécies de peixes (Figuras 3.1 a 3.30.), que são consumidas e/ ou comercializadas na UC estudada. A atividade pesqueira é marcada por um conjunto de etnoconhecimentos que os ribeirinhos detêm acerca das espécies que compõem a ictiofauna local. Esses conhecimentos são utilizados por homens, mulheres, jovens e crianças, sendo repassados para os mais novos por meio da oralidade e através da troca de experiências diretamente na 
Quadro 1

Apetrechos de pesca utilizados pelos ribeirinhos da ResEx Riozinho do Anfrísio, Altamira, Pará, Brasil.

\begin{tabular}{|c|c|}
\hline $\begin{array}{l}\text { Apetrechos } \\
\text { de Pesca }\end{array}$ & Descrição \\
\hline Zagaia & $\begin{array}{l}\text { Consiste de uma haste de madeira leve com um tridente de ferro fixado } \\
\text { em sua ponta. Serve também para captura de quelônios (tracajás). }\end{array}$ \\
\hline Malhadeira & $\begin{array}{l}\text { É uma rede com malha de tamanho variado. Geralmente é utilizada } \\
\text { para captura de peixes grandes, como surubim, pescada e fidalgo. }\end{array}$ \\
\hline Caniço & Linha e anzol presos a uma haste de madeira flexível. \\
\hline Tarrafa & $\begin{array}{l}\text { É uma rede de malha menor, geralmente utilizada para capturar pequenos } \\
\text { peixes (piabas) para serem usados como iscas para a captura de espécies } \\
\text { maiores. }\end{array}$ \\
\hline Tela ou linha & É uma linha de nylon com anzol na ponta. \\
\hline Espinhel & $\begin{array}{l}\text { Consiste de uma linha central com várias linhas menores contendo cada } \\
\text { uma um anzol. Cada ponta da linha central fica aderida em lados opostos } \\
\text { do rio. Os anzóis das linhas menores ficam submersos na água. }\end{array}$ \\
\hline Tiradeira & $\begin{array}{l}\text { Corresponde a uma linha central com diversas linhas menores com } \\
\text { anzóis. Cada ponta da linha central fica aderida a um galho. As linhas } \\
\text { menores ficam dispersas pela linha central suspensa, onde cada uma } \\
\text { contém um anzol com isca. Essas linhas menores ficam acima da } \\
\text { coluna d'água. Os peixes saltam da água para pegarem as iscas e são } \\
\text { então capturados. }\end{array}$ \\
\hline Arco e flecha & $\begin{array}{l}\text { Arco: madeira flexível com um cordão para impulsionar a flecha. } \\
\text { Flecha: consiste de uma haste de uma planta herbácea contendo uma } \\
\text { ponta de ferro. }\end{array}$ \\
\hline Mergulho & Captura direta de quelônios na água. \\
\hline
\end{tabular}

natureza, no fazer cotidiano. O conhecimento acumulado envolve diferentes aspectos da ictiofauna (ver Quadro 2) e alguns desses saberes populares (Quadro 3) se assemelham aos conhecimentos científicos registrados na literatura (Feldberg et al. 2003 apud Teixeira 2008, Godoi 2004, Oliveira et al. 2004), demonstrando que os ribeirinhos detêm um profundo conhecimento da natureza local, e que o mesmo deve ser reconhecido como uma forma de saber oriunda da relação natureza e sociedade, onde esta envolve, como na perspectiva de Lévi-Strauss (1976), uma observação acurada, uma pesquisa minuciosa.

Esses conhecimentos podem ser essencialmente úteis em programas de manejo e de estudos científicos nas áreas de biologia básica e história natural das espécies; os quais, se desenvolvidos em caráter interdisciplinar e a partir da interação entre Ciência e Etnociência, poderão produzir efeitos positivos para a elaboração de políticas 

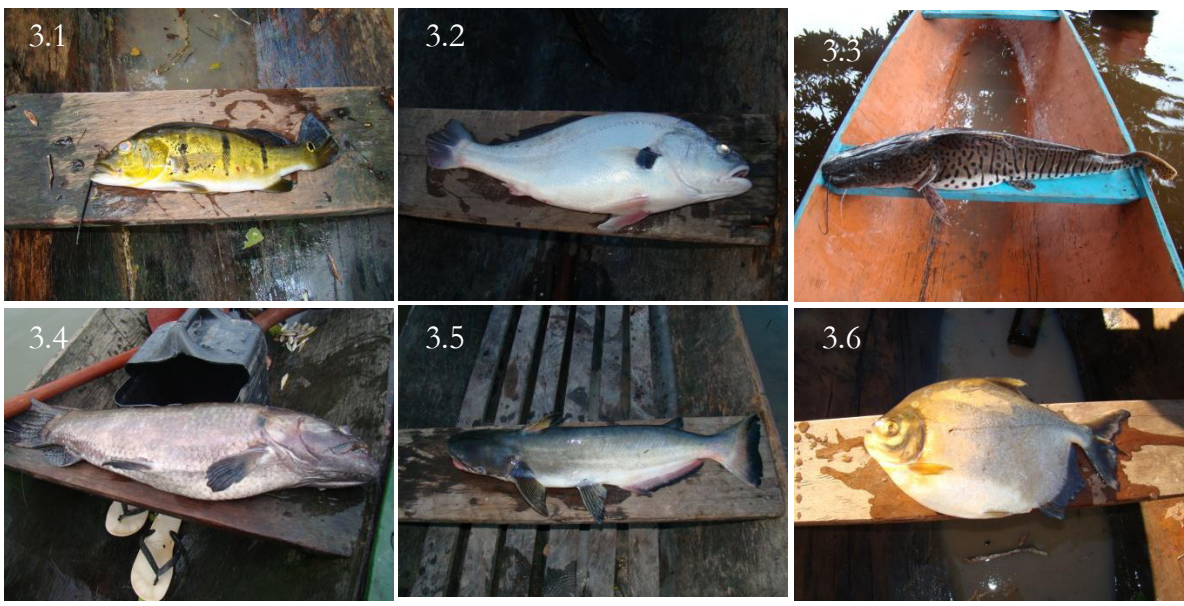

Figura 3.1 a 3.6 - Peixes consumidos e comercializados na ResEx Riozinho do Anfrísio, Pará, Brasil. 3.1) Tucunaré (Cichla melaniae); 3.2) Pescada (Plagioscion squamosissimus); 3.3) Surubim (Psendoplatystoma fasciatum); 3.4) Trairão (Hoplias aimara); 3.5) Fidalgo (Ageneiosus inermis); 3.6) Pacu branco (Myleus torquatus). Fotos: FBB.
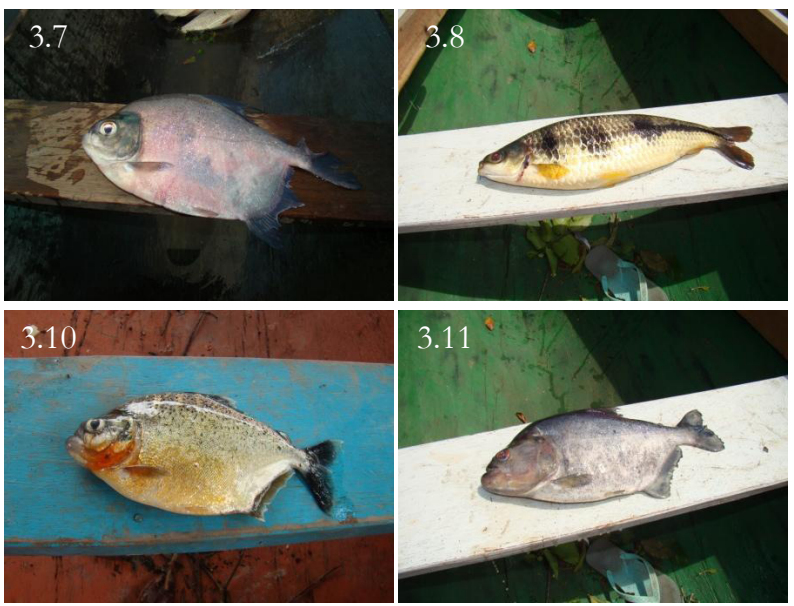
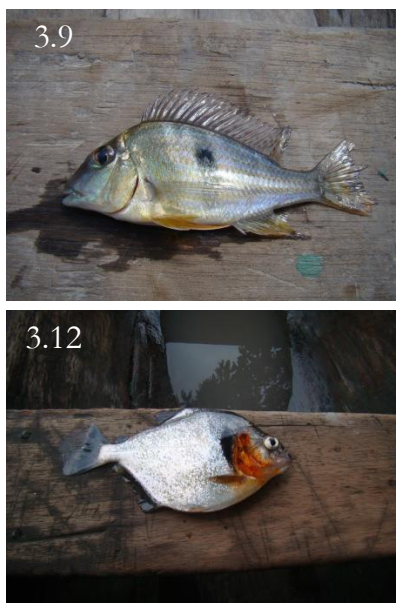

Figura 3.7 a 3.12 - Peixes consumidos e comercializados na ResEx Riozinho do Anfrísio, Pará, Brasil. 3.7) Pacu preto (Piaractus brachypomus); 3.8) Piau (Leporinus sp.); 3.9) Caratinga (Geophagus altifrons); 3.10) Piranha mafurá (Serrasalmus bumeralis); 3.11) Piranha preta (Serrasalmus rhombeus); 3.12) Piranha caju (Serrasalmus manueli). Fotos: FBB. 

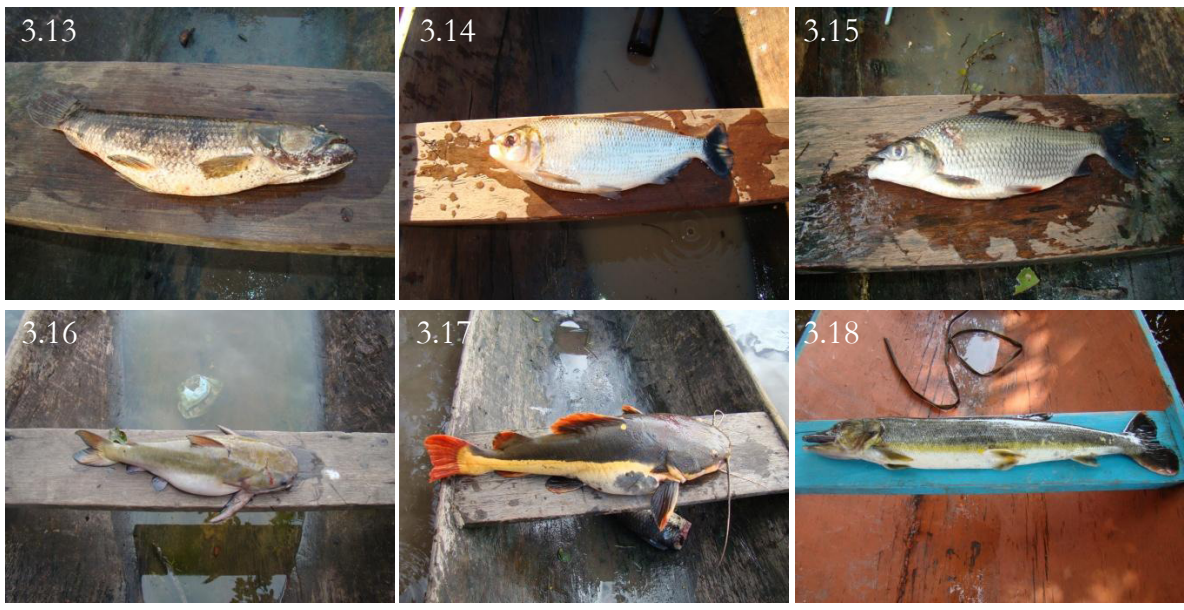

Figura 3.13 a 3.18 - Peixes consumidos e comercializados na ResEx Riozinho do Anfrísio, Pará, Brasil. 3.13 Traíra (Hoplias malabaricus); 3.14) Matrinxã (Brycon falcatus); 3.15 Curimatá (Prochilodus nigricans); 3.16) Pocomon (Tocantinsia piresi); 3.17) Pirarara (Phractocephalus hemioliopterus); 3.18) Mambará (Boulengerella cuvieri). Fotos: FBB.
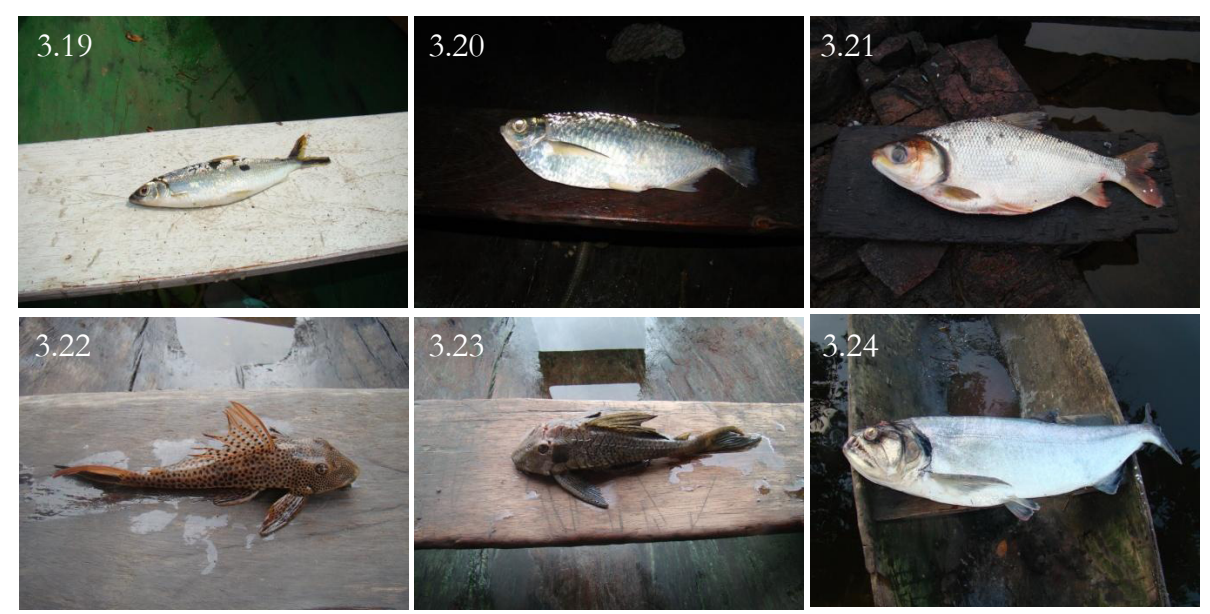

Figura 3.19 a 3.24 - Peixes consumidos e comercializados na ResEx Riozinho do Anfrísio, Pará, Brasil. 3.19) Flexeira (Hemiodus unimaculatus); 3.20) Sardinha (Triportheus sp.); 3.21) Ariduia (Prochilodus nigricans); 3.22) Cari (Scobinancistrus pariolispus); 3.23) Cari preto (Hypostomus cf. plecostomus); 3.24) Cachorra (Hydrolycus armatus). Fotos: FBB. 

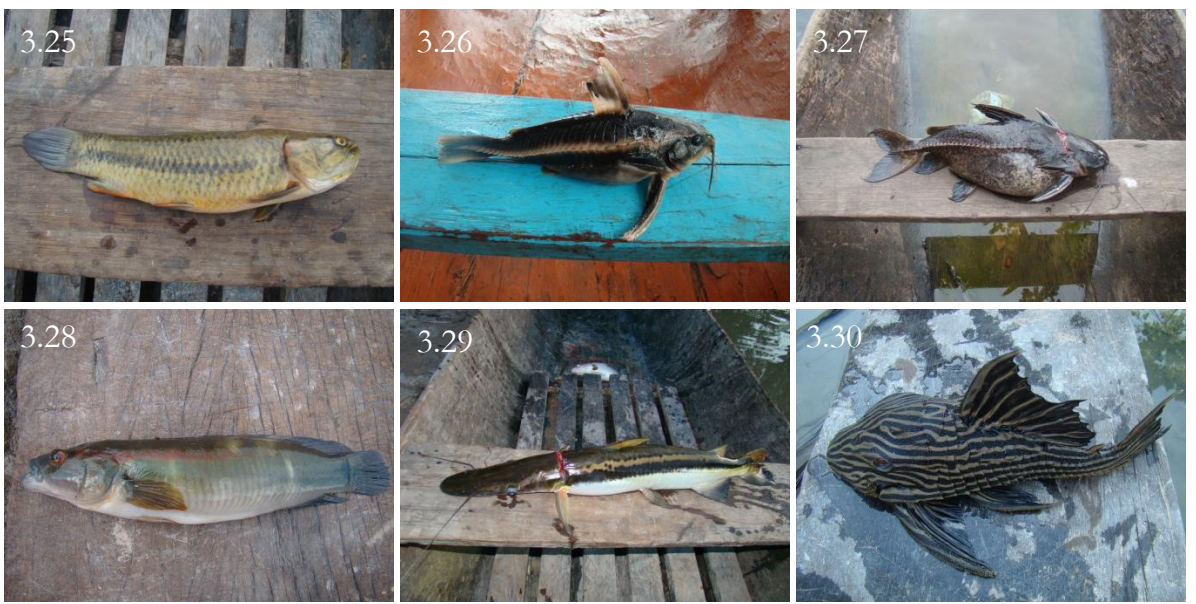

Figura 3.25 a 3.30 - Peixes consumidos e comercializados na ResEx Riozinho do Anfrísio, Pará, Brasil. 3.25) Jeiju (Erythrinus erythrinus); 3.26) Charroque (Platydoras costatus), 3.27) Cuiucuiu (Lithodoras dorsalis); 3.28) Sabão (Crenicichla gr. reticulata); 3.29) Bico de pato (Sorubim trigonocephalus); 3.30) Boi de botas (Panaque aff. nigrolineatus). Fotos: FBB.

públicas e gestão de recursos naturais em AP's (Figura 4).

Os ribeirinhos utilizam o termo "pontos de pesca" para designarem os locais considerados bons para pescar; na maioria das vezes esses locais são tidos como um segredo do pescador, que não os revela nem mesmo para os parentes próximos. Trata-se de um lugar especial descoberto pelo pescador onde pode ser encontrado um determinado tipo de peixe com maior frequência. Esses locais recebem tratamento diferenciado. No final do inverno os pescadores fazem a "limpeza" desses locais; esse processo consiste na retirada da vegetação do entorno para facilitar a pescaria durante o verão. $\mathrm{O}$ termo "pesqueiro" foi outra nomenclatura usada, tendo o mesmo significado de ponto de pesca. Tais locais são considerados importantes para o acesso ao recurso pesqueiro, os quais são identificados por meio de alguma característica natural do lugar, como uma pedra, uma árvore, um "furo" etc. Os termos "ponto de pesca" e "pesqueiro" igualmente aparecem em outros estudos, como os conduzidos por Saldanha (2005) e Silva (2007). A seguir um relato de um informante acerca de um pesqueiro.
"Só eu conheço meus pesqueiros. Eu vou, estudo o local, observo, depois marco esse local e no final de junho volto para fazer a limpeza. Todo verão eu volto lá. Passo seis meses sem ir lá para dar tempo de aparecer muito peixe. Eu, por exemplo, tenho 45 pesqueiros só de tucunaré.” (Sr. C., morador da ResEx).

Em relação à ecologia trófica, os ribeirinhos são capazes de detalhar a preferência alimentar de cada espécie e distinguem a época do ano em que cada uma ocorre com maior frequên- 
Quadro 2

Etnoespécies de peixes consumidas e comercializadas* no Riozinho do Anfrísio, ecologia trófica, habitat, instrumentos de pesca mais utilizados por espécie e comportamento peculiar ("ciência”), segundo os entrevistados.

\begin{tabular}{|c|c|c|c|c|c|}
\hline Etnoespécies & Nome científico & Ecologia trófica & Habitat & Instrumentos de pesca & "Ciência" \\
\hline Tucunaré* & Cicbla melaniae & Peixe (piaba) & Pedral, baixo de praia & Tela & $\begin{array}{l}\text { "Quando tá de filhote não consegue pegar. Para onde o grande vai, os fil- } \\
\text { hotes vão atrás. O grande abre a boca, entram os filhotes e ele afunda com } \\
\text { os filhotes na boca". "Quando percebe que está sendo muito pescado, os } \\
\text { outros mudam de local e horário". } \\
\end{array}$ \\
\hline Pescada branca* & Plagioscion squamosissimus & Peixe (piaba) & Poço, fundo & Tela, malhadeira & $\begin{array}{l}\text { "Muda de horário conforme a lua". "Quando o fato está perto da boca, não } \\
\text { pega isca". "Quando estão cantando por volta das } 18 \text { horas, fica difícil pegar". }\end{array}$ \\
\hline Surubim* & Pseudoplatystoma fasciatum & Peixe & $\begin{array}{l}\text { Fundo, poço, baixo de } \\
\text { praia }\end{array}$ & Tela, espinhel & "Faz cama em baixo de praia" \\
\hline Trairão* & Hoplias aimara & Peixe & $\begin{array}{l}\text { Pedral, lago e folhiço } \\
\text { na beira do rio }\end{array}$ & Tela, caniço & $\begin{array}{l}\text { "Quando chove pode colocar a isca na boca e ele não pega". "Gosta de sol } \\
\text { quente". No verão, quando chove, ele engrossa o bico e não pega isca" }\end{array}$ \\
\hline Fidalgo* & Ageneiosus inermis & Peixe & Fundo, poço & Tela, malhadeira & - \\
\hline Pacu branco & Myleus torquatus & Frutas, flores e formigas & Igapó e fundo do rio & $\begin{array}{l}\text { Arco e flecha, caniço, } \\
\text { tiradeira }\end{array}$ & $\begin{array}{l}\text { "Anda encima da água". "Depois da chuva, gosta de comer formigas que } \\
\text { caem das árvores" }\end{array}$ \\
\hline Pacu preto & Piaractus brachypomus & $?$ & ? & $?$ & - \\
\hline Caratinga & Geophagus altifrons & $?$ & $?$ & $?$ & - \\
\hline Piau & Leporinus sp. & Lodo, frutas e ramos & $\begin{array}{l}\text { Superfície e fundo, } \\
\text { igapó }\end{array}$ & $\begin{array}{l}\text { Arco e flecha, caniço, } \\
\text { tela, tarrafa }\end{array}$ & "Não gosta de zuada. Tem que ficar quieto para pegar" \\
\hline Piranha camari & Serrasalmus sp. & $\begin{array}{l}\text { Peixe, carne de outros } \\
\text { animais e frutas }\end{array}$ & Em qualquer lugar & Tela e caniço & "Gosta de zuada" \\
\hline Piranha mafurá & Serrasalmus bumeralis & $\begin{array}{l}\text { Peixe, carne de outros } \\
\text { animais }\end{array}$ & Em qualquer lugar & Tela e caniço & - \\
\hline Piranha preta & Serrasalmus rhombeus & $\begin{array}{l}\text { Peixe, carne de outros } \\
\text { animais }\end{array}$ & Em qualquer lugar & Tela e caniço & - \\
\hline Piranha caju & Serrasalmus manueli & $\begin{array}{l}\text { Peixe, carne de outros } \\
\text { animais }\end{array}$ & Em qualquer lugar & Tela e caniço & - \\
\hline Traira & Hoplias malabaricus & Peixe & Pedral, lama e lagoa & Caniço e tela & - \\
\hline Matrinxã & Brycon falcatus & $\begin{array}{l}\text { Peixes, frutas, sapos, cobras } \\
\text { e lagartos }\end{array}$ & $\begin{array}{l}\text { Superfície do rio, } \\
\text { igapó }\end{array}$ & $\begin{array}{l}\text { Arco e flecha, tiradeira, } \\
\text { caniço }\end{array}$ & "Forma bando e quando cai bicho ou fruta das árvores, faz festa" \\
\hline Curimatá & Procbilodus nigricans & Lodo, ramos & $\begin{array}{l}\text { Pedral, baixo de praia } \\
\text { e superfície }\end{array}$ & $\begin{array}{l}\text { Arco e flexa, malha- } \\
\text { deira, tarrafa }\end{array}$ & $\begin{array}{l}\text { "Com banzeiro e batido na água ela afunda e não boia mais". "É um peixe } \\
\text { que não tem dente. Chupa lodo justamente porque não tem dentes". "Se } \\
\text { alguém flechar na boca de um dos peixes do bando em piracema, nunca } \\
\text { mais eles voltam pra fazer piracema naquele lugar". }\end{array}$ \\
\hline Pocomon (Capadinho) & Tocantinsia piresi & Peixe, fruta, carne e mariposas & Poço, fundo & Tela, caniço, tiradeira & "Durante a noite fica em cima da água, durante o dia fica no fundo" \\
\hline Pirarara & Phractocephalus hemioliopterus & $\begin{array}{l}\text { Peixe, carne de outros } \\
\text { animais e crustáceos }\end{array}$ & Fundo, poço & Tela, espinhel & - \\
\hline Mambará (Caibo) & Boulengerella cuvieri & Peixes (piaba) & Superfície e pedral & Tela & $\begin{array}{l}\text { "Quando pega uma piaba sai correndo por cima da água para ter mais } \\
\text { apoio para engolir" }\end{array}$ \\
\hline
\end{tabular}




\begin{tabular}{l|l|l|l|l|l}
\hline Flexeira & Hemiodus unimaculatus & Lodo, ramos & Superfície e fundo & $\begin{array}{l}\text { Tela, caniço e arco e } \\
\text { flecha }\end{array}$ & "Forma bando" \\
\hline Sardinha & Triportheus sp. & Frutas, folhas e flores & Superfície & Caniço & - \\
\hline $\begin{array}{l}\text { Braço de moça } \\
\text { (Mandi) }\end{array}$ & Hemisorubim sp. & Peixes (piaba) e frutas & Poço & Tela & - \\
\hline Ariduia & Prochilodus nigricans & Lodo e lama & Lago, meio do rio & Arco e flecha, malhadeira & - \\
\hline Cari & Squaliforma emarginata & Lodo & Pedral & Tarrafa & "Forma bando. Se tiver costume com malhadeira, passa por cima" \\
\hline Cari preto & Hypostomus cf. plecostomus & & & & - \\
\hline Cachorra & Hydrolycus armatus & Peixe (piaba) & Poço, pedral & Tela e malhadeira & - \\
\hline Jeiju & Erythrinus erythrinus & Peixe & Lagoa, grota, igapó & Caniço, tela & $\begin{array}{l}\text { "Se muda do poço que está acabando água. Utiliza uma folha para fazer } \\
\text { esse comportamento. Solta espuma para ficar mais liso" }\end{array}$ \\
\hline Charroque (Corró) & Platydoras costatus & Lodo, piaba & Loca de pedra & Tarrafa & - \\
\hline Barba-chata & Pirinampus pirinampus & Peixe & Fundo & Tela & - \\
\hline Branquinha & Família Curimatidae & Lodo, frutas e peixes (piaba) & Em qualquer lugar & Caniço & - \\
\hline Cuiucuiu & Lithodoras dorsalis & Frutas e peixes (piaba) & & Tela & - \\
\hline Sabão & Crenicicbla gr. reticulata & & & & - \\
\hline Bico de pato & Sorubim trigonocephalus & & & Tarrafa & - \\
\hline Boi de botas & Panaque aff. nigrolineatus & - & Fundo do rio & - \\
\hline
\end{tabular}


Quadro 3

Cognição comparada referente aos conhecimentos dos aspectos etnoecológicos e comportamentais dos peixes consumidos e comercializados na ResEx Riozinho do Anfrísio, Altamira, Pará, Brasil.

\begin{tabular}{|c|c|}
\hline Citação dos pescadores & Literatura científica \\
\hline $\begin{array}{l}\text { "O tucunaré quando tá de filhote não } \\
\text { conseguimos pegar. Para onde o grande } \\
\text { vai, os filhotes vão atrás. O grande abre } \\
\text { a boca, entram os filhotes e ele afunda } \\
\text { com os filhotes na boca". }\end{array}$ & $\begin{array}{l}\text { O cuidado parental, assim como a guarda } \\
\text { de ovos e larvas são marcantes entre os } \\
\text { indivíduos da Família Cichlidae, sendo } \\
\text { este papel desempenhado pelas fêmeas. } \\
\text { (Feldberg et al. } 2003 \text { apud. Teixeira 2008). }\end{array}$ \\
\hline $\begin{array}{l}\text { "A matrinxã come de tudo: peixes, frutas, } \\
\text { sapos, cobras e lagartos e outros bichos } \\
\text { que caem das árvores". }\end{array}$ & $\begin{array}{l}\text { Segundo Godoi (2004), Brycon falcatus } \\
\text { apresenta uma dieta onívora, alimentan- } \\
\text { do-se de insetos e outros animais que } \\
\text { caem das árvores das matas ciliares. } \\
\text { Comem flores, frutos, crustáceos, insetos, } \\
\text { peixes, lagartixas, etc. }\end{array}$ \\
\hline "A curimatá se alimenta de lodo e lama". & $\begin{array}{l}\text { De acordo com Godoi (2004), a dieta } \\
\text { de Prochilodus nigricans é do tipo iliófaga, } \\
\text { com predomínio de sedimentos e algas. } \\
\text { Segundo estudos realizados por Oliveira } \\
\text { et al. (2004), essa espécie de peixe se } \\
\text { alimenta principalmente de sedimentos } \\
\text { e detritos, com prevalência de algas da } \\
\text { família Bacillariophyceae. }\end{array}$ \\
\hline $\begin{array}{l}\text { "A traíra se alimenta de peixe e vive em } \\
\text { lagoas, lama e pedral". }\end{array}$ & $\begin{array}{l}\text { Hoplias aff. malabaricus tem hábito alimen- } \\
\text { tar piscívoro e ocorre principalmente em } \\
\text { lagos (Ferreira et al. 1998). }\end{array}$ \\
\hline $\begin{array}{l}\text { "O surubim ocorre no Riozinho durante } \\
\text { todo o ano. Se alimenta de peixe e vive } \\
\text { no fundo do rio e embaixo de praia". }\end{array}$ & $\begin{array}{l}\text { Segundo Ferreira et al. (1998), Psendoplatys- } \\
\text { toma fasciatum tem hábito piscívoro. De } \\
\text { acordo com as entrevistas realizadas por } \\
\text { Silvano et al. (2001) no Alto Rio Juruá, } \\
\text { esta espécie ocorre tanto no verão como } \\
\text { no inverno. }\end{array}$ \\
\hline
\end{tabular}

cia. Ao longo do dia, identificam em que ambientes os peixes permanecem, aumentando a chance de captura. A seguir alguns relatos que revelam o saber dos pescadores.

"O pacu é um peixe que gosta de fruta. Embira, guajará, embaúba, bananinha, veludo, são alguns exemplos das frutas que ele gosta de comer"
(Sr. R., morador da ResEx).

"O surubim gosta de comer peixe e faz uma cama embaixo da praia" (Sr. S., morador da ResEx).

"Quando o tucunaré está de filhote, ninguém consegue pegar. Ele abre a boca, os filhotes entram e depois afunda. Para onde o grande vai os filhotes vão atrás" (Sr. F., morador da ResEx). 


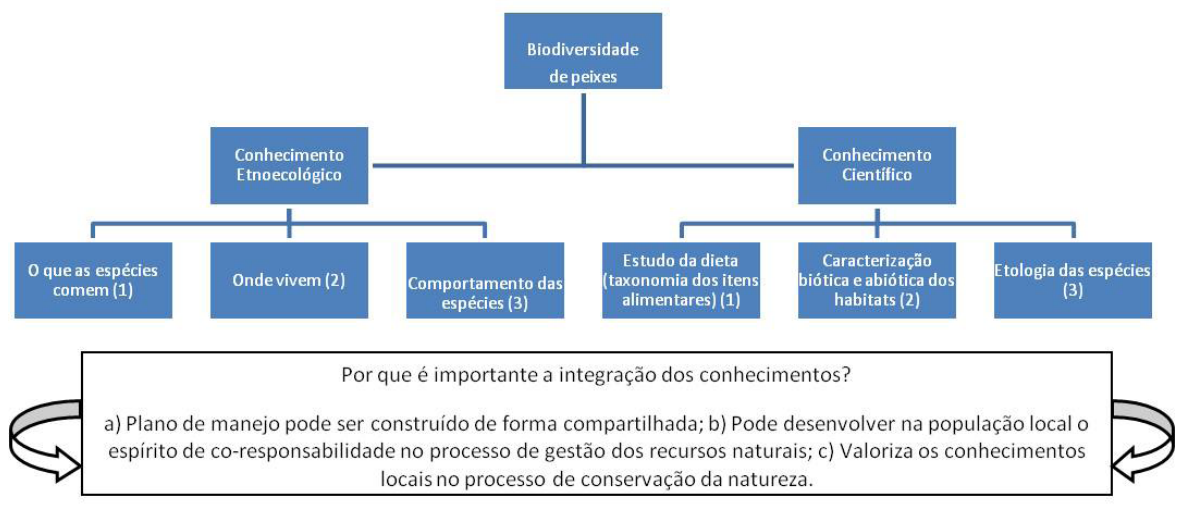

Figura 4 - Esquema mostrando como a integração dos conhecimentos pode ser útil no processo de gestão de uma AP.

Quanto à morfologia externa dos peixes, os pescadores têm uma forma própria de dividir o corpo desses animais, atribuindo nomes específicos. Na Figura 5 encontrase um peixe fictício com a nomenclatura local. Os ribeirinhos reconhecem os peixes que apresentam algum tipo de parentesco, quando dizem, por exemplo, que existem vários tipos de piranhas ou de pacus.

Diversas regras culturais incrementam o mundo da pesca no Riozinho do Anfrísio. Os mitos revelam-se como mecanismos importantes que ajudam a reinventar o cotidiano da relação dos pescadores entre si e destes com a natureza. Alguns entrevistados relataram que a Mãe d'água e o Cabeça de Cuia são dois seres que enchem de mistério esse complexo mundo da pesca e atuam como protetores das águas, castigando aqueles que usam os recursos pesqueiros de maneira destrutiva. Esses mitos funcionam como mecanismo que tanto serve para organizar a pesca como, de certo modo, para controlar os recursos. Informantes relataram que o Cabeça de Cuia quando está revoltado chega a matar pessoas, virar embarcações e assustar as virgens que vão banhar-se sozinhas nos rios. Silva \& Begossi (2004), assim como neste estudo, também identificaram e relataram a crença nesses seres sobrenaturais por ribeirinhos da região do rio Negro. Furtado (1993) comenta ainda que esses seres se inserem dentro de uma dualidade, explicando que são benéficos para o "filho" (rio, lago, igarapé) e maléficos para quem o espolia ou não o respeita (o ser humano). Galvão (1955) também, em sua obra intitulada "Santos e visagens: Um estudo sobre a religiosidade em Itá, $A M$ ”, descreveu com profundidade como os encantados estão presentes e materializados na vida das populações amazônicas. Alguns moradores disseram acreditar nesses encantados. Abaixo segue o relato de um interlocutor:

"Não gosto de sobreviver da vida dos peixinhos [se referindo à pesca comercial]. Já vi um exemplo com es- 


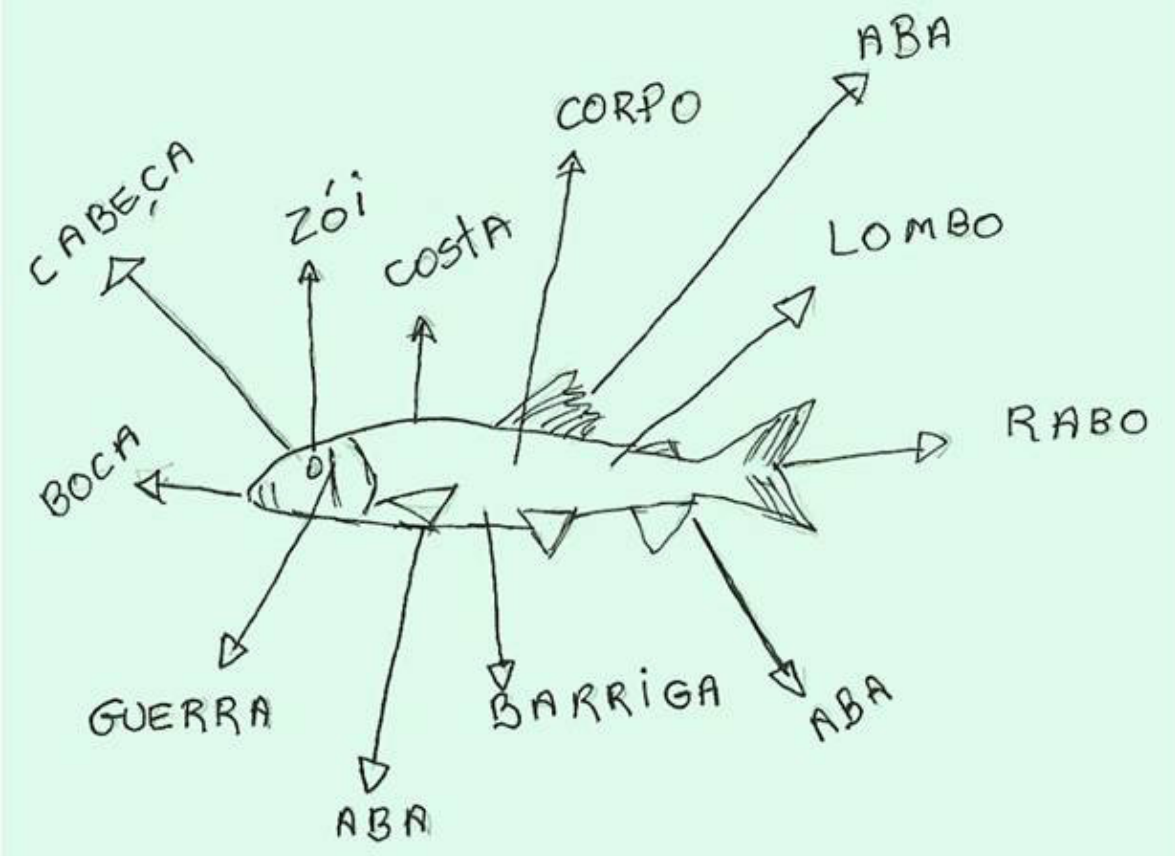

Figura 5 - Etnomorfologia externa de um peixe fictício. Desenho adaptado, feito por um pescador do Riozinho do Anfrísio.

pinhel que havia pegado dois peixes grandes. Depois o espinhel começou a balançar de repente e quando o pessoal foi tirar os peixes, não tinha nada. Os peixes sumiram. Acho que foi a Mãe d’água ou o Cabeça de Cuia. Meu pai passou pela experiência de ver o Cabeça de Cuia. Ele tinha dois olhos" (Sr. M., morador da ResEx).

O universo da pesca no Riozinho do Anfrísio não está condicionado apenas aos conhecimentos obtidos ao longo da vida. É preciso também, segundo os interlocutores, ter sorte para ser um bom pescador. A "panema", nesse caso, é o termo utilizado para designar os pescadores despossuídos de sorte na pesca. Este estado pode ser motivado por diversos fatores, como por exemplo, encontrar uma mulher grávida.

Outra situação registrada foi o relato do ato de "comer escama de peixe". Essa ação acontece quando vários homens saem juntos para pescar. É caracterizada pelo ato de esconder a escama do peixe embaixo da língua sem que o pescador que o pescou perceba. Isso ocorre quando alguém do grupo não obtém sucesso na pescaria. Com essa atitude, a pessoa que esconde a escama passa a ter êxito na pesca, e o dono do peixe enfrenta o insucesso. Apesar dos entrevistados terem relatado tal situação, todos 
colocaram que nunca tiveram esse tipo de comportamento.

A pesca de subsistência é na maioria dos casos uma atividade masculina. Quando não há caça para comer, é dos homens a obrigação de sair todos os dias para buscar o peixe que alimenta a família. Às mulheres, cabe a tarefa de tratar o peixe trazido pelo companheiro ou outro membro do núcleo familiar. O ritual é o mesmo em todos os lugares da Reserva - os homens tão logo regressam com o pescado, as mulheres descem para os portos a fim de tratar o peixe obtido.

$O$ peixe que alimenta serve também como presente, que com frequência é ofertado para o vizinho. Em geral este peixe é enviado por alguma pessoa da família que está oferecendo e uma das regras é entregá-lo já pronto para ser preparado e consumido. Essa atitude fortalece os laços de amizade e ajuda a preservar a política de boa vizinhança entre os comunitários, atitude que vai ao encontro da teoria Maussiana sobre a reciprocidade (Mauss 2003).

\section{CONSIDERAÇÕES FINAIS}

A pesca no Riozinho do Anfrísio se caracteriza como uma atividade importante, com relevante papel social, cultural, econômico e de sobrevivência. A riqueza de detalhes acerca dos conhecimentos apresentados pelos pescadores demonstra a estreita relação que existe entre os ribeirinhos e a natureza. Este conhecimento não deve ser negligenciado, pois constitui eficaz ferramenta para a efetivação de

estratégias de conservação que estejam embasadas numa perspectiva dialógica entre Estado e as comunidades locais. Estas populações, uma vez envolvidas nas diferentes ações de conservação que venham a ser promovidas pelo órgão gestor (neste caso, o Instituto Chico Mendes de Conservação da Biodiversidade-ICMBio), podem se tornar aliadas imprescindíveis de uma boa gestão dos recursos naturais, uma vez que a perspectiva da conservação, não como a concebemos, faz parte de seu modo de vida.

As cosmologias, os saberes locais e as regras culturais, que demarcam uma identidade, não constituem meros saberes, mas um patrimônio cultural que deve ser valorizado no âmbito não apenas da gestão dos recursos pesqueiros, mas em todos os sentidos da gestão da UC. Sem este reconhecimento, como apontam alguns estudos, dificilmente uma Reserva Extrativista conseguirá alcançar seus reais objetivos, uma vez que a valorização dos modos de vida das comunidades locais constitui uma das suas finalidades.

É relevante destacar ainda a necessidade da efetivação de estudos interdisciplinares, que envolvam biólogos, antropólogos e etnoecólogos para avaliar com maior profundidade a situação da pesca numa visão sistêmica, enfocando não apenas os aspectos etnoecológicos, mas em termos exploratórios, com vistas a evitar uma possível sobrepesca, uma vez que, além da subsistência, tal atividade é desenvolvida com função comercial. 


\section{AGRADECIMENTOS}

Agradeço a antropóloga Jane Felipe Beltrão pelo honroso convite para escrever para a Amazônica: Revista de Antropologia. Não poderia deixar de agradecer ao povo do Riozinho do Anfrísio, pela acolhida e por compartilhar seus conhecimentos. Ao Instituto Chico Mendes de Conservação da Biodiversidade (ICMBio) e UFPA, pelo apoio ao trabalho de campo. Ao Prof. Dr. Henrique Miguel Pereira, do Centro de Biologia Ambiental da Universidade de Lisboa, pela concessão de bolsa de pesquisa pelo prejeto LUPA.

\section{NOTAS}

${ }^{1}$ Neste texto optei pela utilização do termo ribeirinho, mesmo ciente da polêmica do uso desses termos generalizados, que têm uma certa inserção no debate socioambiental e na luta por direitos, mas os povos locais se autorreconhecem e se autodenominam de beiradeiros.

${ }^{2} \mathrm{O}$ termo colocação corresponde ao lugar onde vive a família e onde se desenvolve boa parte das atividades produtivas, como a agricultura. Esta denominação era utilizada com maior ênfase na época da borracha, entre o fim do século XIX e meados do século XX.

${ }^{3}$ Trata-se dos regatões ou donos de barco da região que fazem a intermediação entre os pescadores artesanais do Riozinho do Anfrísio e os compradores de peixe.

\section{REFERÊNCIAS}

Almeida, O. T., K. Lorenzen \& D. G. Mcgrath. 2003. Commercial fishing in the Brazilian Amazon: regional differentiation in the fleet characteristics and efficiency. Fisheries Management and Ecology 10:109-115.
Alves, R. R. da N., G. A. P. Filho \& Y. C. C. Lima 2007. Snakes used in ethnomedicine in northeast Brazil. Environment, Development and Sustainability 9:455-464.

Amorozo, M. C. de M. \& R. B. Viertler. 2008. A abordagem qualitativa na coleta e análise de dados etnobotânicos, in Métodos e técnicas na pesquisa etnobotânica. Editado por U. P. de Albuquerque, R. F. P. de Lucena e L. V. F. C. da Cunha, pp. 73-91. São Paulo: UNESP.

Batista, V. S., A. J.Inhamuns, C. E. C. Freitas \& D.Freire-Brasil. 1998. Characterization of the fishery in river communities in the low-Solimões/high-Amazon region. Fisheries Management and Ecology 5:419-435.

Begossi, A. 2006. The ethnoecology of Caiçara metapopulations (Atlantic Forest, Brazil): Ecological concepts and questions. Journal of Ethnobiology and Ethnomedicine 2(1):40. Disponível em http://www.ethnobiomed.com/content/2/1/40.

Begossi, A. \& R. A. M. Silvano. 2008. Ecology and ethnoecology of dusky grouper [garoupa, Epinephelus marginatus (Lowe, 1834)] along the coast of Brazil. Journal of Ethnobiology and Ethnomedicine 4(1):20. Disponível em http://www.ethnobiomed. com/content/4/1/20.

Costa-Neto, E. M. \& J. G. W. Marques. 2000. Etnoictiologia dos pescadores artesanais de Siribinha, município de Conde (Bahia): Aspectos relacionados com a etologia dos peixes. Acta Scientarium 22(2): 553-560.

Derman, B. \& A.Ferguson. 1995. Human rights, environment, and development: the dispossession of fishing communities on Lake Malawi. Human Ecology 23 (2):125-142.

Feldberg, E., J. I. R. Porto, \& L. A. C. Bertollo. 2003. Chromosomal changes and adaptation of cichlid fishes during evolution, in Fish adaptation. Editado por A. L. Val \& B. G. Kapoor, pp. 285-308. New Dehli \& New York: Science Publishers. 
Ferreira, E. J. G., J. A. S. Zuanon \& G. M. Santos. 1998. Peixes comerciais do Médio Amazonas: Região de Santarém, Pará. Coleção Meio Ambiente, Série Estudos Pesca. Brasília: Edições IBAMA.

Furtado, L. G. 1993. Pescadores do rio Amazonas: Um estudo antropológico da pesca ribeirinha numa área amazônica. Coleção Eduardo Galvão. Belém: Museu Paraense Emílio Goeldi.

Galvão, E. 1955. Santos e visagens: Um estudo da vida religiosa de Itá, $A M$. São Paulo: Companhia Editora Nacional.

Geertz, C. 2008. A interpretação das culturas. Rio de Janeiro: Editora LTC.

Godoi, D. S. de. 2004. Diversidade e hábitos alimentares de peixes de um córrego afluente do Rio Teles Pires, Carlinda, MT, drenagem do Rio Tapajós. Dissertação de Mestrado, Universidade Estadual Paulista, Jaboticabal, SP, Brasil.

IBGE - Instituto Brasileiro de Geografia e Estatística. Censo dos municípios brasileiros. Disponível em: http://www.ibge.gov.br. (Acessado em 06 de Março de 2010).

Levi-Strauss, C. 1976. O pensamento selvagem. São Paulo: Editora Nacional.

Malinowski, B. 1978. Argonautas do Pacifico Ocidental: Um relato do empreendimento e da aventura dos arquipélagos da Nova Guiné Melanésia. São Paulo: Abril Cultural.

Mauss, M. 2003. Sociologia e Antropologia. Tradução: Paulo Neves. São Paulo: Cosac \& Naif.

Marques, J. G. W. 2001. Pescando pescadores: Ciência e etnociência numa perspectiva ecológica. São Paulo: NUPAUB/USP.

1995. Etnoictiologia: pescando pescadores nas águas da transdisciplinaridade, in Encontro Brasileiro de Ictiologia 11. Resumos, pp.1-41. Campinas: Sociedade Brasileira de Ictiologia.

1991. Aspectos ecológicos na etnoictiologia dos pescadores do Complexo Estuarino-lagunar
Mundaú-Manguaba, Alagoas, Brasil. Tese de Doutorado, Universidade Estadual de Campinas, SP, Brasil.

Martins, J. B.1996. Observação participante: Uma abordagem metodológica para a Psicologia escolar. Semina: Ciências, Sociedade e Humanidade 17(3): 266-273.

Murrieta, R. S. S. 2001. A mística do pirarucu: Pesca, ethos e paisagem em comunidades rurais do Baixo Amazonas. Horizontes Antropológicos 7(16): 113-130.

Murrieta, R. S. S., M. Batistoni \& N. N. Pedroso-Jr. 2004. Consumo alimentar e ecologia em populações ribeirinhas na Região da Floresta Nacional de Caxiuanã (PA). Boletim Rede Amarônia 3(1):85-94.

Nazarea, V. D. 1999. Introduction. A view from a point: Ethnoecology as situated knowledge, in Ethnoecology: situated knowledge/ located lives, pp.3-20. Editado por V. D. Nazarea. Arizona: The University of Arizona Press.

Oliveira, A. H. M., P. S.Braz, E. E. Marques \& R. J. Oliveira. 2004. Dieta do curimbatá Prochilodus nigricans no rio Tocantins, região da UHE Luís Eduardo Magalhães, nas fases rio e lago, in Resumos do XXV Congresso Brasileiro de Zoologia. Brasília.

Ramires, M., S. M. G. Molina \& N. Hanazaki. 2007. Etnoecologia caiçara: O conhecimento dos pescadores artesanais sobre aspectos ecológicos da pesca. Biotemas 20 (1): 101-113.

Rozzi, R., F. Massardo, C. B. Anderson, K. Heidinger \& J. A. Silander Jr. 2006. Ten principles for biocultural conservation at the southern tip of the Americas: the approach of the Omora Ethnobotanical Park. Ecology and Society 11(1): 43.

Saldanha, I. R. R. 2005. Espacos, recursos e conbecimento tradicional dos pescadores de manjuba (Anchoviella lepidentostole) em Iguape/SP. Dissertação de Mestrado, Universidade de 
São Paulo, São Paulo, SP, Brasil.

Silva, A. L. 2007. Comida de gente: Preferências e tabus alimentares entre os ribeirinhos do médio rio Negro (Amazonas, Brasil). Revista de Antropologia da USP 50(1): 125-179.

Silva, A. L. \& A. Begossi. 2004. Uso de recursos por ribeirinhos no médio rio $\mathrm{Ne}-$ gro, in Ecologia de pescadores da Mata Atlântica e da Amazônia, pp.89-148. Organizado por A. Begossi. São Paulo: HUCITEC/ NUPAUB.

Silvano, R.A.M. 2004. Pesca artesanal e etnoictiologia, in Ecologia de pescadores da Mata Atlantica e da Amazônia. Organizado por A. Begossi, pp. 185-220. São Paulo: HUCITEC.

Silvano, R.A.M., O. Oyakawa, B. do Amaral \& A. Begossi. 2001. Peixes do alto rio Juruá (Amazonas, Brasil). São Paulo: EdUSP.

Silvano, R.A.M., \& A. Begossi. 2005. Local knowledge on a cosmopolitan fish ethnoecology of Pomatomus saltatrix (Pomotomidae) in Brazil and Australia. Fisheries Research 71:43-59.

Smith, N. J. H. 1979. A pesca no rio Amazonas. Manaus: CNPq.

Spradley, J. P. 1980. Participant observation. New York: Holti, Rinehart \& Winston.

Teixeira, W. G. 2008. Identificação e caracterização de sequencias repetidas de DNA no genoma de peixes ciclídeos do gênero Cichla. Dissertação de Mestrado, Universidade Estadual Paulista, Botucatu, SP, Brasil.

Toledo, V. M. 2001. Biodiversity and indigenous peoples, in Encyclopedia of Biodiversity. Editado por S. A. Levin, pp. 330-340. San Diego: Academic Press.

Toledo, V. M., B. Ortiz-Espejel, L. Cortés, P. Moguel \& M. de J. Ordoñez. 2003. The multiple use of tropical forest by indigenous peoples in México: a case of adaptive management. Ecology and Society 7 (3):9.
Velásquez, C., A. V. Boas \& S. Schwartzman. 2006. Desafio para a gestão ambiental integrada em território de fronteira agrícola no oeste do Pará. Revista de Administração Pública 40 (6): 1061-1075.

Xu, J., E. Ma, D. Tashi, Y. Fu, Z. Lu \& D. Melick. 2006. Integrating sacred knowledge for conservation: Cultures and landscapes in southwest China. Ecology and Society 10(2): 7.

Recebido em 01/05/2012.

Aprovado em 30/07/2012. 